\title{
Substitution of Small Dam System in Water Conservancy Construction
}

\author{
Jingchen Sun \\ North China Electricity Power University No.2, Beinong Road, Huilongguan, Changping District, \\ Beijing, 102206, P.R. China \\ 1561157799@163.com
}

\begin{abstract}
Keywords: Water conservancy construction; Small dam system; Zambezi River; Multi-objective decision; Principal component analysis
\end{abstract}

\begin{abstract}
In water conservancy construction, large-scale dams in disrepair, need to be removed, engineers began to study with a small dam system to replace large dam construction. In this paper, the Kaliba dam is taken as an example to discuss the selection of the number of small dam systems. we use multi-objective decision-making model . Firstly we have selected 14 indicators to assess the dam's water management in four aspects: power generation, water storage, flood control and ecology. Then we divide the number of dams into ten groups. Combined with the hydrological data of the Zambezi River over the years, we use the principal component analysis method to calculate the comprehensive score of these ten programs. At last, we find the score is the maximum when the number of dams system is 16 . The study method of our establishing model can be applied in other area relativeto architectural engineering, such as urban and rural planning.
\end{abstract}

\section{Introduction}

A dam can be powered by a small hydropower station If a place of river water or streams is sufficient, then micro-hydropower will be the most economical way to provide electricity for rural communities. The villagers themselves can build and manage this small hydropower station. In China, India and Nepal, tens of thousands of micro hydroelectric power stations are supplying electricity to some towns and villages.

The Kariba Dam on the Zambezi River is one of the larger dams in Africa. The Zambezi River Authority hopes to build a number of small dam systems between 10 and 20 in place of the current Kaliba Dam .Security and environmental protection should also be in consideration. This paper gives a detailed selection of the number of small dams.

\section{The Definition of each Index}

In order to measure small dam system in dicators of water management ability, we evaluate it from four methods: Generating, Water storage, Flood control and Ecology. From the four methods, we choose 14 indexes. they are named as $F 1 \sim F 14$, the number of dams scheme is named as $P 1$.the number of dams scheme $P 1$ is 10 , the number of dams scheme $P 2$ is 11 , the rest can be done in the same manner. Details are defined [3] as follows:

Generating. Installed capacity: a generator set's rated power that a hydropower station install actually: $F 1$.Efficient generation: the power of an operating hydropower station is used for generating: $F 2$. Adjustable load: when the supplying power change, the range of load it can sustain: F3.

Water Storage. Gross water storage: the ideal water storage of the lake which is surrounded by the dam: $F 4$.Efficient water storage: the actual water storage if we consider safety principle: $F 5$.Rainfall: the rain drop fall into river without any loss: $F 6$. Runoff: get through a cross section of the river water in a certain period of time: $F 7$.

Flood Control. Water storage capacity: the index of measuring flood control water level: F8 .Water discharged flow: the discharge flow from reservoir not only promises Flood control 
function but also let water flows normally in watercourse: $F 9$. The risk assessment of food control: have an quantitative evaluation to The risk of food control: $F 10$.

Ecology. Tourist spot: the dam's construction will damage Zambezi Rive bank landscape: F11 . Bio diversity: the construction will break the bio diversity: $F 12$.Prairie and marsh: the flood damage the prairie and marsh: F13.Immigration: the loss to immigration: F14.

\section{The Number of Dams in Multiply Dam System}

The Kariba Dam is located in about $300 \mathrm{~km}$ southeast of Zambia's capital, stretch across the border between the two countries, Zambia and Zimbabwe. After The Kariba Dam is completed, it impounds completely from1958to1958. The following is a detailed data [4] of the reservoir.

Table 1 The data about The Kariba Dam

\begin{tabular}{|l|l|}
\hline Discharge Capacity of Spillway & $9500 \mathrm{~m} 3 / \mathrm{s}$ \\
\hline Length of Reservoir & $280 \mathrm{~km}$ \\
\hline Minimum Retention Level & $488.50 \mathrm{~m}$ \\
\hline Minimum Operating Level & $475.50 \mathrm{~m}$ \\
\hline Total Storage & $180.6 \mathrm{~km} 3$ \\
\hline Maximum Surface Area & $5577 \mathrm{~m} 2$ \\
\hline Depth of Stilling Pool & $78 \mathrm{~m}$ \\
\hline Volume of Stilling Pool & $410 \times 106 \mathrm{~m} 3$ \\
\hline Kariba South Bank Power Cavern & $6 \times 117.5 \mathrm{MW}=705 \mathrm{MW}$ max capacity \\
\hline Kariba North Bank Power Cavern & $4 \times 153.5 \mathrm{MW}=615 \mathrm{MW}$ max capacity \\
\hline Total Generation Capacity & $1320 \mathrm{MW}$ \\
\hline
\end{tabular}

After analyzing and assessing the The Kariba Dam and the Zambezi River historical rate, We got the original data of multi-objective decision model

Table 2 Original data

\begin{tabular}{|l|l|l|r|l|l|l|l|l|l|l|l|l|l|l|}
\hline & F1 & F2 & F3 & F4 & F5 & F6 & F7 & F8 & F9 & F10 & F11 & F12 & F13 & F14 \\
\hline P1 & 1205 & 234 & 4.68 & 180.6 & 64.8 & 816 & 2232 & 60.8 & 950 & 10 & -93 & -642.9 & -213 & -22 \\
\hline P2 & 1237 & 271 & 6.33 & 179.6 & 68 & 876 & 2243 & 43.61 & 990 & 9 & -100 & -715.7 & -219 & -30. \\
\hline P3 & 1269 & 308 & 8.23 & 181.6 & 71.2 & 996 & 2254 & 41.18 & 1030 & 8 & -107 & -693.6 & -225 & -38. \\
\hline P4 & 1301 & 346 & 10.38 & 181.6 & 74.5 & 966 & 2265 & 50.63 & 1070 & 7 & -114 & -620.6 & -231 & -46. \\
\hline P5 & 1333 & 383 & 12.77 & 182.6 & 77.8 & 936 & 2276 & 50.92 & 1110 & 6 & -121 & -796.0 & -237 & -55. \\
\hline P6 & 1365 & 620 & 15.42 & 178.6 & 81 & 906 & 2287 & 30.65 & 1150 & 5 & -128 & -659.9 & -243 & -63. \\
\hline P7 & 1397 & 658 & 18.32 & 182.6 & 84.2 & 876 & 2298 & 9.23 & 1190 & 4 & -135 & -619.9 & -249 & -71. \\
\hline P8 & 1429 & 495 & 21.46 & 181.6 & 87.5 & 846 & 2309 & 69.37 & 1230 & 3 & -142 & -733.9 & -255 & -80. \\
\hline P9 & 1461 & 532 & 24.85 & 180.6 & 90.7 & 816 & 2320 & 35.2 & 1270 & 2 & -149 & -794.3 & -261 & -88. \\
\hline P10 & 1493 & 570 & 28.5 & 179.6 & 94 & 786 & 2331 & 33.85 & 1310 & 1 & -156 & -672.3 & -267 & -96. \\
\hline
\end{tabular}

The Main Component Analysis

Standardized Processing to the Original Data. Assuming that the number of principal component analysis[1] index variables is $\mathrm{m}$. they are $x 1, x 2$,there are $n$ evaluation objects, the ${ }^{i}$ th evaluation

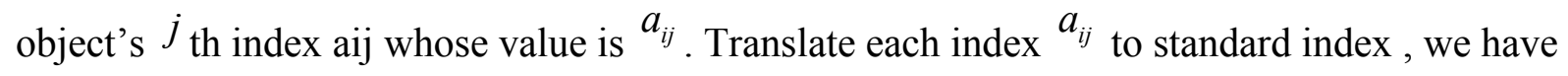


$\bar{a}_{i j}=\frac{a_{i j}-u}{s_{j}}, i=1,2, \ldots m ; j=1,2, \ldots m$

In the formula, $u_{j}=\frac{1}{n} \sum_{i=1}^{n} a_{i j}, s=\sqrt{\frac{1}{n-1} \sum_{i=1}^{n}\left(a_{i j}-u_{j}\right)^{2}}, j=1,2, \ldots m$, so $u_{j} s_{j}$ is the $\mathrm{j}$ th index's sample average and sample standard deviation. Correspondingly we call:

$$
\tilde{x}_{j}=\frac{x_{j}-u_{j}}{s_{j}}, j=1,2, \ldots m
$$

as Standard index variable.

Calculate Correlation Index Matrix R. correlation coefficient matrix: $R=\left(r_{i j}\right)_{m \times n}$ we have

$$
r_{i j}=\frac{\sum_{k=1}^{n} \tilde{a}_{k i} \tilde{a}_{k j}}{n-1}, i, j=1,2, \ldots m,
$$

From the formula $r_{i j}=r_{j i}, r_{i j}$ is the $i$ th and the $j$ th correlation index.

Calculate Eigenvalue and Eigenvector. calculate correlation index matrix $\mathrm{R}$ eigenvalue $\lambda_{1} \geq \lambda_{2} \geq \ldots \geq \lambda_{m} \geq 0$ and their eigenvector and their eigenvecto $u_{1}, u_{2}, \ldots u_{m}$, among them $u_{j}=\left[u_{1 j}, u_{2 j}, \ldots u_{m j}\right]^{T}$,m new index variables are composed by eigenvector.

$$
\begin{aligned}
& y_{1}=u_{11} \tilde{x}_{1}+u_{21} \tilde{x}_{2}+\ldots+u_{m 1} \tilde{x}_{m} \\
& y_{1}=u_{12} \tilde{x}_{1}+u_{22} \tilde{x}_{2}+\ldots+u_{m 2} \tilde{x_{m}} \\
& \ldots \ldots \\
& y_{m}=u_{1 m} \tilde{x}_{1}+u_{2 m} \tilde{x_{2}}+\ldots+u_{m m} \tilde{x_{m}}
\end{aligned}
$$

In these formula $y_{1}$ is the first principal component, $y 2$ is the second... $y_{m}$ is the $\mathrm{m}$ th. The principal components of the 14 evaluation indices were analyzed by matlab software. The first few eigenvectors of the correlation coefficient matrix and their contributions were shown in the table:

Table 3 Principal Component Analysis result

\begin{tabular}{|c|c|c|c|}
\hline & $\begin{array}{c}\text { characteri } \\
\text { stic root }\end{array}$ & $\begin{array}{c}\text { the rate of } \\
\text { contribution }\end{array}$ & $\begin{array}{c}\text { accumulative } \\
\text { contribution rate }\end{array}$ \\
\hline 1 & 10.1298 & 72.3558 & 72.3558 \\
\hline 2 & 1.4731 & 10.5219 & 82.8777 \\
\hline 3 & 1.2707 & 9.0761 & 91.9538 \\
\hline 4 & 0.5930 & 4.2354 & 96.1982 \\
\hline 5 & 0.4217 & 3.0123 & 99.2015 \\
\hline 6 & 0.1111 & 0.7936 & 99.9951 \\
\hline
\end{tabular}

As can be seen from the table, the cumulative contribution rate of the first three eigenvalues of more than $90 \%$, principal component analysis is very effective. So we select the first five principal components (cumulative contribution rate of $99 \%$ ) for comprehensive evaluation.

Choose p principal Components. Calculate eigenvalue $p\left(p_{i} m\right)$ 's message contribute rate, accumulated contribution rate[2], we call 


$$
b_{j}=\frac{\lambda_{i}}{\sum_{j=1}^{p} \lambda_{k}}, j=1,2, \ldots m
$$

as principal component $y_{1}$ 's message contribute rate, meanwhile. we have

$$
\alpha_{p}=\frac{\sum_{k=1}^{p} \lambda_{k}}{\sum_{k=1}^{m} \lambda_{k}}
$$

As principal component $y_{1}, y_{2}, \ldots y_{p}$ accumulated contribution rate. When $\alpha_{p}$ is close to 1(we usualy let $\alpha=085,090,095)$,we choose the first $p$ index variables $y_{1}, y_{2}, \ldots y_{p}$ as $p$ principal components index variables to replace the original $\mathrm{m}$ principal components, then we can make comprehensively analyzed to $\mathrm{p}$ principal component[6].

- After calculating, we work out comprehensive score:

$$
Z=\sum_{j=1}^{p} b_{i} y_{i}
$$

\section{Conclusion}

From Table 3 we calculated the data, the first principal component mainly reflects the first four indicators (Installed capacity Effcient generation Adjustable load Gross water storag) information, The second principal component mainly reflects the water storage index, the third principal component mainly reflects the flood control index, the fourth and fifth principal components mainly reflect the ecological impact indicators.

The principal component comprehensive evaluation model was constructed with the weight contribution rate of five principal components as the following formula

$$
Z=1.101298 y_{1}+0.1473 y_{2}+0.1270 y_{3}+0.0593 y_{4}+0.0421 y_{5}
$$

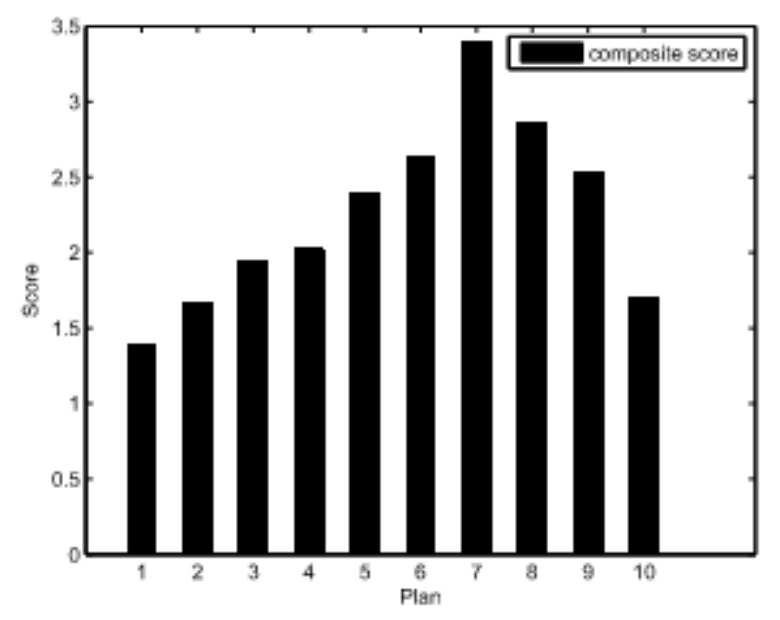

Figure 1. Comprehensive score

Model Sensitivity Analysis. The model is based on an ideal situation that parameters is certain. So here we will use the sensitivity analysis to determine the extent to which our model is affected by these parameters. And we will choose the installed capacity as the impact of this factor[5]. If we change the installed capacity, we will get different results. The schematic diagram is as follows: 
Fig. 2 shows installed capacity in accordance with the number of small dams in descending order of 10 programs score, and the total score of the scheme is the highest at this time. The installed capacity decreases gradually according to the number of small dams, and the scores of the ten schemes are the highest. The sensitivity analysis results are in good agreement with the actual situation.
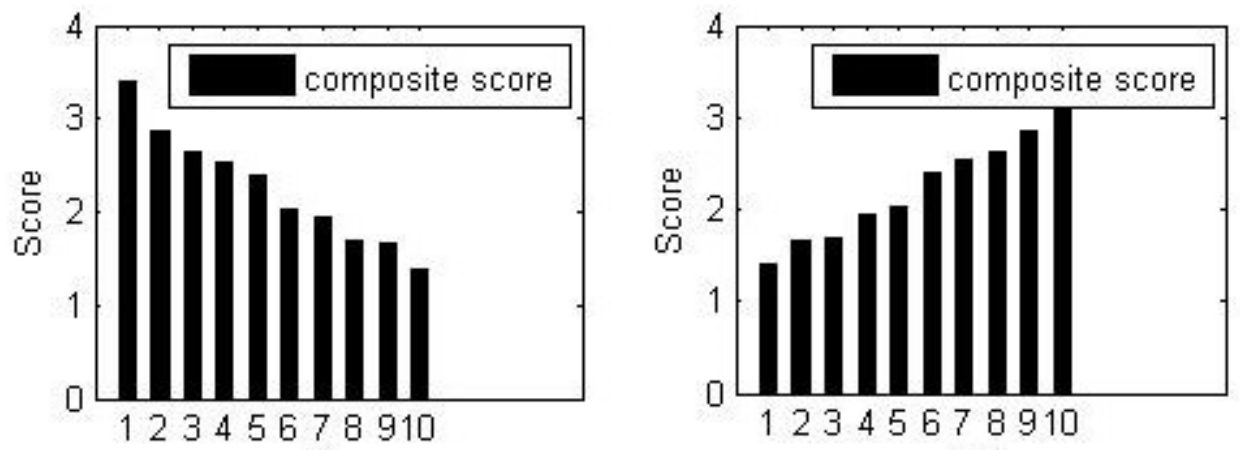

Figure 2. The effect of installed capcity

Taking into account the structure of the model, analogy to the above process, a reasonable change in other variables will be similar to the phenomenon, but the impact of varying degrees. As the overall target is determined, the relevant indicators are determined accordingly, and the final result is the optimal solution which the number of dams is 16 in system.

Strength and Weaknes. This system can improve the utilization rate of water energy. This system can improve the comprehensive economic benefits of the dam. However, this model still has the following drawbacks:

We did not consider less populated parts of immigration policy, and ignoring the cascade dams system impact on the local climate. Refer to the data itself exists system error in processing data process summary of the inevitable accidental error, reduces the accuracy of the data.

\section{References}

[1] Marler R T, Arora J S. Survey of multi-objective optimization methods for engineering [J]. Structural and multidisciplinary optimization, 2004, 26(6): 369-395.

[2] Jolliffe I. Principal component analysis [M]. John Wiley Sons, Ltd, 2002.

[3] Liu J, Zang C, Tian S, et al. Water conservancy projects in China: Achievements, challenges and way forward [J]. Global Environmental Change-human and Policy Dimensions, 2013, 23(3): 633-643.

[4] Moore A E, Cotterill F P D, Main M P L, et al. The Zambezi River [J]. Large rivers: Geomorphology and Management, 2007: 311-332.

[5] Winsemius, H. C., et al. "Comparison of two model approaches in the Zambezi river basin with regard to model reliability and identifiability." Hydrology and Earth System Sciences 10.3 (2006): 339-352.

[6] Tumbare, Michael James. "Managing Lake Kariba sustainably: threats and challenges." Management of Environmental Quality: An International Journal19.6 (2013): 731-739. 